\title{
correspondence
}

\section{Conserving uranium}

SIR,-.-The exposition by John Davies (1 December, page 376) of the virtues of the CANDU reactor thorium cycle as a possible alternative to fast reactors does indeed cover matters "being discussed in undergraduate lectures twenty years ago". It does so with a splendid disregard for the present status of the technologies involved.

Recently the experimental fast reactor at Dounreay was shut down after 18 years of successful operation, its original exploratory task complete. An important part of that task was to demonstrate the docile behaviour and ease of control of fast reactors. The UK, France and the USSR are now operating prototype reactors in the 250-350 MW(e) output range. The maturity of the technology is apparent from the fact that the latter two countries have committed the construction of larger units of commercial significance.

The position on the CANDUthorium fuel cycle is well set out in an authoritative manner in the evidence submitted by Atomic Energy of Canada Ltd (AECL) to the Ontario Royal Commission on Electric Power Planning which was published in April of this year. The section on 'Prospects for future CANDU fuel cycles' brings out the elementary fact that "Thorium is a fertile material but contains no fissile isotope". It is therefore proposed to use plutonium recycled from the existing uranium fuels to commence the cycle. Reprocessing of both uranium/ plutonium and ${ }^{232} \mathrm{Th} /{ }^{233} \mathrm{U}$ fuels is therefore required-a more complex situation than arises with the fast reactor.

It is concluded by AECL that "the overall development and demonstration programme can be completed during the 1990s". This makes it quite clear that we are dealing with a technology which is not yet available even on a pilot scale, and which is unlikely to avcid the problems of MUF (material unaccounted for) and possible illicit diversion to weapons. Incidentally, freshly reprocessed ${ }^{2 * 3} U$ is not automatically protected by gamma radiation, since this arises from ${ }^{232} \mathrm{U}$ daughter produots, and takes about 10 days to build up to embarrassing levels requiring elaborate remote handling.

The AECL submission to the Royal Commission also discusses the use of accelerators under the heading of
'Electro-nuclear breeding'. Here it is concluded that "if the cost of uranium were to rise substantially, electronuclear breeding might be economically justified. In any event such systems will not be required until the advanced fuel cycles are fully established so there is ample time for their orderly development". The quotation places the Chalk River work cited by John Davies in its proper perspective.

In Canada, where there is a substantial investment in manufacturing facilities for CANDU reactors (including the heavy water production plants) the progress to the thorium cycle appears naturally as a logical step. At the expense of an initial increase in the rate of usage of uranium a long term benefit can be obtained. In my view it would not be sensible for this country to follow the same course when, with our starting point, (that is with fast reactor technology available) we are in a position to obtain a much larger energy output from the available stocks of uranium. The thorium reserves would of course also be burnable in fast reactors at a much later date if necessary.

D. HICKS

Risley Nuclear Power Development Establishment, UK

\section{Censuring repressive regimes}

SiR,--The letter from Dr Peto and Professor Doll (1 December, page 384) asks several important questions, especially:

- how can busy scientists obtain a dispassionate assessment of alleged oppressive conditions in countries other than their own?

What can they do to mitigate such oppression?

- In particular, is it useful to boycott scientific conferences in such a country?

These were just the questions which we examined in our report Scholarly Freedom and Human Rights, published earlier this year, in association with the British Institute of Human Rights, by Barry Rose. We concluded that the recent development of international human rights law had, for the first time in human history, pro- vided a standard frame of reference, internationally agreed, against which the conduct of public authorities in different countries could be objectively measured. We recommended that there should be set up an independent clearing-house which would collect and evaluate information about such conduct in order that scientists could receive objective and impartial assessments on which they could rely, and we suggested the International Council of Scientific Unions and the International Commission of Jurists, jointly, as suitable bodies to undertake that task.

The ICJ has indicated its willingness in principle to take on its part of this function; the ICSU has not yet completed its examination of the proposal. Meanwhile, Peto and Doll were wise to consult Amnesty International: their sources of information are excellent, and their reports command world-wide respect.

There remains the question of the usefulness of boycotts. So far as I know, there is no evidence that public protest, or an effective boycott, have ever been counter-productive. There is some evidence that, on some occasions, they have influenced oppressive regimes for the better (the case of Dr Mikhail Shtern is a recent example). But in the absence of a full understanding of how the internal affairs of oppressive regimes are conducted, or of controlled experiments with matching samples, we can never know for sure.

The best procedure-at least in my view-would be for reputable international scientific bodies to agree in advance not to hold conferences and congresses in countries whose regimes have been clearly and impartially shown to pursue a consistent policy of oppression towards scientists, scholars and other non-violent citizens. There cannot be many countries which could survive such isolation for long.

This is a subject which has caused many scientists many personal and collective problems in recent years. We hope that the study of the underlying principles which is set out in our report can make its contribution to clarifying those problems, and indicate the directions in which their solution may be found.

\section{Paul Sieghart}

Council for Science and Society.

London, $U K$ 